\title{
ANTIOXIDANT SUPPLEMENTS IN ALZHEIMER'S DEMENTIA AND MILD COGNITIVE IMPAIRMENT: A SYSTEMATIC REVIEW
}

\author{
E.J. Pegg
}

\begin{abstract}
Objective: Current treatments have only a modest effect on impairment in Alzheimer's Dementia (AD) and there is no treatment currently licensed for Mild Cognitive Impairment (MCI). Oxidative stress is postulated to play a role in the pathogenesis of $\mathrm{AD}$ and $\mathrm{MCI}$ and this provides a rationale for treatment with antioxidant supplements. The aim of this review is to evaluate the effect of antioxidant supplements in people with $\mathrm{AD}$ and MCI. Methods: A systematic review of published randomised controlled trials was carried out. 4 electronic databases were searched. Studies were included if they compared the use of a placebo with the following antioxidant supplements in people with AD or MCI: Vitamin e, vitamin c, selenium, alpha lipoic acid, phenols, zinc, curcumin, beta carotene, coenzyme Q10, melatonin. The primary outcome measure was cognitive impairment. Secondary outcome measures included functional impairment, behavioural disturbance and safety. Results: 10 trials were identified which met the inclusion criteria. Outcome data was not suitable for meta-analysis. 5 studies reported a small positive treatment effect on cognition and 1 reported a negative effect. 2 reported a positive treatment effect on functional ability and 1 on behaviour. There were no consistent adverse effects found overall however two studies raised concern of possible worsening of cognition in certain circumstances. Conclusions: The findings of this systematic review do not support the use of antioxidant supplements to slow cognitive, functional or behavioural deterioration in people with AD or MCI. However the majority of included studies had a high or unknown risk of bias. In the one study which had a low overall risk of bias, there was evidence that antioxidant supplements may have a positive effect on functional decline in AD. The overall risk of harm associated with short term antioxidant supplementation appears to be low however caution is warranted. Further studies evaluating the role of oxidative stress in the pathogenesis of $\mathrm{AD}$ are suggested.
\end{abstract}

Key words: Alzheimer's, mild cognitive impairment, antioxidants.

Abbreviations: ADAS: Alzheimer's Disease Assessment Scale; ADAS-cog: Alzheimer's Disease Assessment Scale- cognitive subscale; ADAS-non cog: Alzheimer's Disease Assessment Scale- non cognitive subscale; ADCS-ADL: Alzheimer's Disease Cooperative Study- Activities of Daily Living Inventory; ADRQL: Alzheimer's Disease Related Quality of Life; BDS: Blessed Dementia Scale; BRS: Behaviour Rating Scale for Dementia; CAS: Caregiver Activity Survey; CDR: Clinical Dementia Rating; CDR-SOB: Clinical Dementia Rating- Sum of Boxes; CDT: Clock Drawing Test; CVLT: (learning) California Verbal Learning Test (learning); CVLT: (recall) California Verbal Learning Test (recall); DS: Dependence Scale; EIS Equivalent Institutional Service (subsection of Dependence Scale); GDS: Global Deterioration Scale; MCI-ADLS: Mild Cognitive Impairment Activities of Daily Living Scale; MMSE: Mini Mental State Examination; NINCDS-ADRDA: Alzheimer's Criteria National Institute of Neurological and Communicative Disorders and Stroke and Related Disorders Association; NPI: Neuropsychiatric Inventory; QOLS: Quality of Life Scale; S-PAL: Spatial Paired Associate.

\section{Introduction}

Currently available pharmacological treatments for Alzheimer's Dementia (AD), acetylcholinesterese inhibitors (AChEIs) and memantine, have only a modest effect on cognitive impairment, function and behaviour and there is no treatment currently licensed for Mild Cognitive Impairment (MCI).

The main neuropathological features of $\mathrm{AD}$ are

Corresponding Author: E.J. Pegg, Lancashire Teaching Hospitals NHS Foundation Trust, United Kigdom, emily-pegg@doctors.org.uk accumulation of beta-amyloid plaques and tau containing neurofibrillary tangles. The exact mechanism by which this occurs is complex and has not been fully elucidated however oxidative stress is hypothesised to play a major role by interacting with key processes including mitochondrial dysfunction, inflammation, protein misfolding, calcium homeostasis and metal chelation (1). In view of this, antioxidant therapy has been suggested as a mechanism to slow the progression of cognitive impairment.

Studies have reported increased levels of oxidative damage to DNA and neurons in both $\mathrm{AD}$ and $\mathrm{MCI}(2,3)$ suggesting that oxidative stress might be an important 
cause of initiation and progression of cognitive impairment and AD.

Findings from human studies evaluating the benefit of dietary antioxidants or supplementary antioxidants in slowing cognitive decline have been mixed, with some studies even reporting a negative effect (4).

The overview of the literature suggests that only the effects of Vitamin E supplements on AD have been assessed within the context of a relatively recent systematic review (5). The examination of the effects of other widely used antioxidant supplements have not been a subject of recent systematic reviews. In addition, given the mixed results produced by studies evaluating antioxidant supplements in $\mathrm{AD}$ and $\mathrm{MCI}$, together with potential safety concerns (6-11) and the expanding evidence in this research area, it can be concluded that there are strong grounds to support the need to undertake a comprehensive systematic review which will summarise and compare the effects of all the key antioxidant supplements on $\mathrm{AD}$ and $\mathrm{MCI}$.

The following research questions will be addressed in this systematic review:

In people taking antioxidant supplements with $\mathrm{AD}$ and $\mathrm{MCI}$, what is the effect on:

a) cognitive ability

b) functional ability and behaviour

c) potential side effects

\section{Methods}

This review was conducted and reported based upon PRISMA reporting standards (12).

\section{Search Strategy}

The following databases were searched for eligible papers: PubMed, Embase (1974-February 2015), CINAHL and Cochrane Central Register of Controlled Trials in the Cochrane Library. "Mesh" terms and text words were searched for combinations of dementia, cognitive impairment and each particular antioxidant. Searches were limited to studies conducted in human subjects and written in the English Language.

\section{Eligibility Criteria}

Studies were included if they met the following criteria:

- Population: Adults with AD or MCI diagnosed according to internationally recognised diagnostic criteria e.g. the MMSE or NINCD-ADRDA.

- Intervention: The study design was restricted to Randomised Controlled Trials (RCT). Any dosage of the following antioxidant supplements, either alone or in combination was included: Vitamin e, vitamin c, selenium, alpha lipoic acid, phenols, zinc, curcumin, beta carotene, coenzyme Q10, melatonin.
The first five antioxidants were selected because they are reported to be the most important dietary antioxidants (13). The latter five compounds have also been reported to be important antioxidants.

Subjects taking their own multivitamin tablets were included because a third of the adult population is estimated to take supplements therefore including these participants is potentially reflective of the population.

Subjects taking other pharmacotherapy to slow cognitive decline (i.e. acetyl cholinesterase inhibitors and memantine) were included only if the intervention group was also taking these agents.

Gingko biloba is also a potent antioxidant but it has additional properties, including acting as a monoamine oxidase inhibitor, which could cause confounding therefore it was not included in this review. A Cochrane review did not support its use in $\mathrm{AD}$ (14).

- Comparison: People with AD or MCI not taking antioxidant supplements.

- Outcome: The primary outcome measure was cognitive impairment. Secondary outcome measures included functional impairment, behavioural disturbance and safety.

\section{Exclusion criteria}

- Subjects with dementia in the context of Down's syndrome

- Subjects taking supplements containing additional compounds not listed above

\section{Study selection}

Titles and abstracts of each study were firstly screened against the eligibility criteria of the study. The full texts of studies that were rated as potentially eligible in the title/abstract screening were retrieved, and further screened against the inclusion and exclusion criteria.

\section{Data extraction}

A data extraction sheet was formulated as an Excel spreadsheet. Information was extracted regarding the context of the study (publication year, setting, author), study design (sampling, randomisation, length of follow up, completion rate), participants (age, gender, severity of $\mathrm{AD} / \mathrm{MCI}$, the intervention (type of antioxidant and dose) and outcomes (cognition, function, behaviour/ mood, adverse events, quality of life). Where the data is continuous, standard deviations (SD) were extracted. Any difference between baseline and outcome data was calculated.

\section{Methodological quality assessment}

In order to evaluate bias, the Cochrane Collaboration's tool for assessing risk of bias was used (15). The following 
Table 1

Study characteristics and baseline characteristics of included studies

\begin{tabular}{|c|c|c|c|c|c|}
\hline Study & Setting \& recruitment & $\begin{array}{l}\text { Sample size at } \\
\text { baseline }\end{array}$ & $\begin{array}{l}\text { Age in years (mean, } \\
\text { SD) }\end{array}$ & $\begin{array}{l}\text { gender } \\
\text { (\% female) }\end{array}$ & $\begin{array}{l}\text { Disease severity (shown as mean }+\mathrm{SD} \text { or } \\
\text { median) }\end{array}$ \\
\hline Asayama 2003 (20) & Japan, single centre & $\begin{array}{l}\text { I } 9 \\
\text { P } 11\end{array}$ & All subjects 79.2 (6.4) & $\begin{array}{l}\text { All subjects } \\
85 \%\end{array}$ & $\begin{array}{l}\text { All AD according to DSM-IV and NINCDS-ADR- } \\
\text { DA criteria. I MMSE } 12.6 \text { (7.0), ADAS-cog } 39.8 \\
\text { (35.6), ADAS non-cog 10.6 (6.0). P MMSE } 10.3 \\
\text { (7.5), ADAS-cog } 39.7 \text { (17.1), ADAS-non cog } 7.9 \\
\text { (5.5). }\end{array}$ \\
\hline Brewer 2013 (19) & USA, single centre & $\begin{array}{l}\text { I } ? 30 \\
\text { P } 30\end{array}$ & $\begin{array}{l}\text { I } 65.4(10.16) \\
\text { P } 72.9(7.3)\end{array}$ & $\begin{array}{l}\text { I } 47 \\
\text { P } 63\end{array}$ & $\begin{array}{l}\text { All mild to moderate } \mathrm{AD}^{*} \text { with a Clinical Demen- } \\
\text { tia Rating of } 0.5-1.5 \text { and mean MMSE of } 25.6 \text {. No } \\
\text { further baseline values provided. }\end{array}$ \\
\hline Dysken 2014 (22) & $\begin{array}{l}\text { USA, } 14 \text { veteran medi- } \\
\text { cal centres }\end{array}$ & $\begin{array}{l}\text { I } 151 \\
\text { P } 152\end{array}$ & All subjects 78.8 & $\begin{array}{l}\text { I } 4 \\
\text { P } 2\end{array}$ & $\begin{array}{l}\text { All possible or probable mild to moderate AD* } \\
\text { with MMSE } 12-26 \\
\text { I MMSE } 21.3 \text { (3.3), ADAS-cog } 18.5 \text { (8.8), NPI 7.5, } \\
\text { CAS } 2.7 \\
\text { P MMSE } 20.8 \text { (3.8), ADAS-cog } 19.1 \text { (8.4), NPI 8.0, } \\
\text { CAS } 3.0\end{array}$ \\
\hline Galasko 2012 (4) & USA, 12 centres & $\begin{array}{l}\text { I } 53 \text { (in } 2 \text { groups) } \\
\text { P } 25\end{array}$ & $\begin{array}{l}\text { I1 } 73.6(9.1) \text { I2 } 71.4(8.4) \\
\text { P } 73.2\end{array}$ & $\begin{array}{l}\text { I1 } 46 \text { I } 44 \\
\text { P } 48\end{array}$ & $\begin{array}{l}\text { All probable AD* with MMSE of } 16 \text { or over } \\
\text { E/C/ALA: MMSE } 23.1 \text { (3.9) ADSC-ADL } 61.1 \\
\text { (16.3) } \\
\text { Placebo: MMSE 23.1 (3.4) ADCS-ADL } 65.4(8.7) \\
\text { CoQ: MMSE } 23.3 \text { (4.4) ADSC-ADL } 65.2(12.8)\end{array}$ \\
\hline Lloret 2009 (16) & Spain, single centre & $\begin{array}{l}57 \text { in total (plus } 18 \\
\text { controls) }\end{array}$ & Not disclosed & Not disclosed & $\begin{array}{l}\text { Mild, moderate or severe AD according to } \\
\text { NINCDS-ADRA and the GDS. }\end{array}$ \\
\hline Ringman 2012 (21) & USA, single centre & $\begin{array}{l}\text { I } 24 \text { (in } 2 \text { groups) } \\
\text { P } 12\end{array}$ & completers 73.5 & $\begin{array}{l}\text { I } 68 \\
\text { P } 55\end{array}$ & $\begin{array}{l}\text { All mild to moderate AD according to DSM-IV } \\
\text { and NINCDS-ADRDA criteria } \\
\text { P: MMSE 23.2 (2.3), ADAS-Cog 18.2 (4.9), NPI } \\
\text { score } 8.5 \text { (12.4) ADCS-ADL } 66.7 \text { (3.6) } \\
\text { Curcumin 2mg: MMSE 21.4 (3.2), ADAS-cog } 20.9 \\
\text { (7.4), NPI 8.9 (9.6), ADCS-ADL 60.3 (10.9) } \\
\text { Curcumin 4mg: MMSE 22.8 (3.4), ADAS-cog } 19.3 \\
\text { (3.4), NPI 11.7 (16.9), ADCA-ADL } 61 \text { (8.4) }\end{array}$ \\
\hline Sano 1996 (18) & USA, 23 centres & $\begin{array}{l}\text { I } 84 \\
\text { P } 85\end{array}$ & $\begin{array}{l}\text { I } 73.4(7.8) \\
\text { P } 73.5(8.3)\end{array}$ & $\begin{array}{l}\text { I } 65.9 \\
\text { P } 65.5\end{array}$ & $\begin{array}{l}\text { All probable moderate AD (CDR of } 2) \\
\text { I MMSE } 11.3(5.7), \text { BDS } 6.6(2.1), \text { CDR } 11.3(1.3) \\
\text { P MMSE 13.3(4.9), BDS } 6.1(2.1), \text { CDR } 10.9(1.2)\end{array}$ \\
\hline $\begin{array}{l}\text { Alavi Naeini } 2013 \\
\text { (23) }\end{array}$ & Iran, retirement clubs & $\begin{array}{l}\text { I } ? 127 \\
\text { P ?129 }\end{array}$ & All subjects $60-75$ & $\begin{array}{l}\text { I } 64 \\
\text { P } 72\end{array}$ & $\begin{array}{l}\text { MCI 21-26 on MMSE. No further baseline values } \\
\text { provided. }\end{array}$ \\
\hline Krikorian 2009 (17) & $\begin{array}{l}\text { USA, community via } \\
\text { newspaper advert }\end{array}$ & $\begin{array}{l}\text { I } 7 \\
\text { P } 5\end{array}$ & All subjects 78.2 & $\begin{array}{l}\text { All subjects } \\
33 \%\end{array}$ & $\begin{array}{l}\text { All MCI according to CDR. } \\
\text { I CDR SOB 1, CVLT (learning) 35.2, CVLT (recall) } \\
\text { 6.0, S-PAL 2.8, GDS 3.0 P CDR SOB 1, CVLT (lear- } \\
\text { ning) 33.2, CVLT (recall) 5.4, S-PAL 2.4, GDS } 7.8\end{array}$ \\
\hline Petersen 2005 (24) & $\begin{array}{l}\text { Canada and USA, } 96 \\
\text { centres }\end{array}$ & $\begin{array}{l}\text { I } 257 \\
\text { P } 259\end{array}$ & All subjects 72.9 (7.3) & $\begin{array}{l}\text { I } 46 \\
\text { P } 47\end{array}$ & $\begin{array}{l}\text { All MCI defined by CDR of 0.5, MMSE 24-30. I } \\
\text { MMSE } 27.20 \text { (1.9), ADAS-cog 11.48 (4.4), CDR } \\
\text { SOB 1.78 (0.8), GDS 2.64 (0.6), ADLS 45.82 (4.6). P } \\
\text { MMSE 27.35 (1.8), ADAS-cog 11.3 (4.2), CDR SOB } \\
\text { 1.87 (0.8), GDS 2.72 (0.6), ADLS } 45.87(5.2)\end{array}$ \\
\hline
\end{tabular}

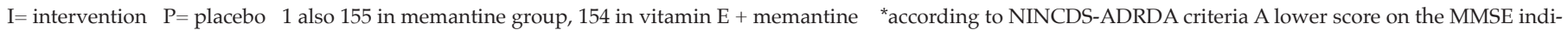

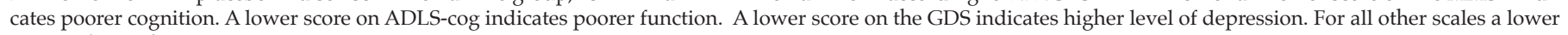
score indicates better outcome.

domains of each study were assessed: Randomisation, allocation concealment, blinding, blinding of outcome assessment, incomplete outcome data, selective outcome reporting, sample size and any other potential sources of bias.

\section{Data synthesis}

Due to a wide variety of assessment scales used as well as differences in the way in which data was reported, it was not possible to combine outcomes. Furthermore, the majority of the studies reported the data as a change in scores from baseline to follow up therefore the data was not suitable for meta-analysis. A descriptive analysis is suitable for the purposes of this review because a number of antioxidants were used at low frequencies.

\section{Results}

A trial flow diagram is shown below. In total 7605 studies were identified after a search of electronic databases as described in the methodology section. This figure excludes 508 studies which were not published in the English Language. There were 7561 studies excluded after screening the title and/or abstract. A frequent reason for exclusion was the study design i.e. very few studies were randomised controlled trials. Animal 


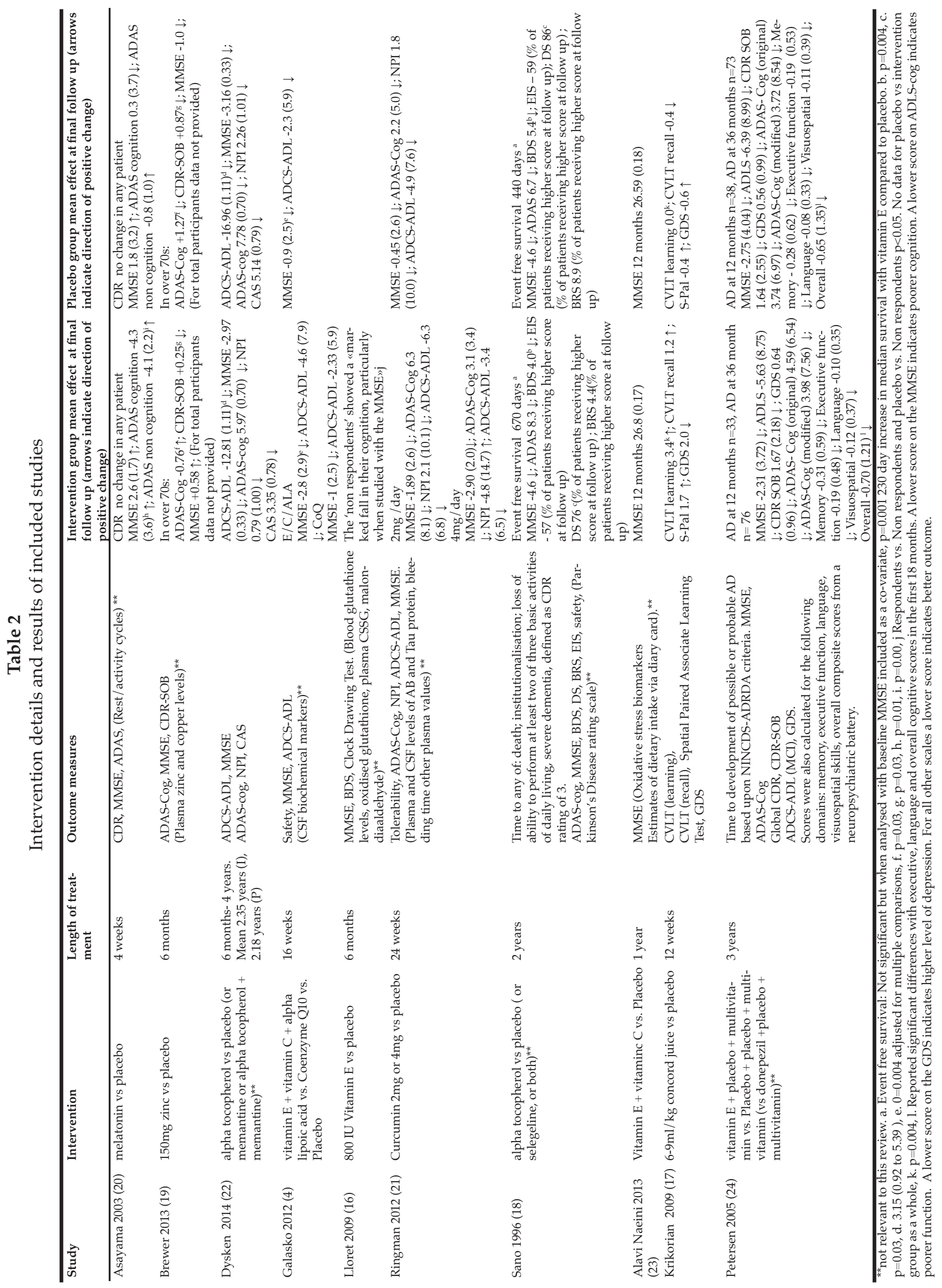


studies were also excluded, as were studies which used combination compounds where one of the substances was not an antioxidant. After duplicates were removed, 20 studies were read in further detail to assess for eligibility. A total of 10 studies remained which met the inclusion criteria.

A total of 1483 participants were randomised and intervention antioxidants included: Zinc, curcumin, melatonin, vitamin E, vitamin $\mathrm{C}$, alpha lipoic acid, coenzyme Q10, polyphenols and flavonoids.

Key descriptive details of the included studies are shown in table 1.

\section{Outcome measures}

\section{Cognition}

In total, 12 different outcome measures were used to assess cognition or to objectively grade the severity of Alzheimer's disease. 7 studies used one or more methods of assessing cognition and 3 used only the MMSE. Details of the outcome measures used can be seen in tables 1 and 2.

Overall, 5 of the 10 studies reported a statistically significant improvement or a slower rate of deterioration in one or more cognitive assessments in the intervention group compared to the control group at the end of the study (16-20). In 4 of these studies participants had AD and in 1 they had MCI (17). In 2 of the studies with a positive treatment effect however, the difference was found following a post hoc analysis where the groups were divided by age (19) or whether there was plasma evidence of a response to antioxidant therapy (16).

Of the studies with a positive treatment effect on cognition where more than one measure was used, the significant effect was not seen across all of the measures in any of the studies.

Of concern is that 1 study reported a statistically significant worsening in cognition in the intervention group compared to the placebo group (4). Another study reported a worsening of cognition in the people who did not have a plasma response to the antioxidant, compared to the placebo group (16).

Only 1 of the 3 studies in which participants had $\mathrm{MCI}$ evaluated time to development of dementia as an outcome measure. There was no significant difference between the groups found.

\section{Activities of daily living / functional assessment}

In total 5 studies used an assessment of ADLs or function as an outcome measure using 4 different scales. 4 of the studies involved participants with $\mathrm{AD}$ patients and $1 \mathrm{MCI}$.

Overall 2 studies reported a positive treatment effect $(18,22)$ and the other 3 found no difference between the intervention and control groups.

\section{Mood/ behavioural disturbance}

In total 4 studies included a measure of mood or behavioural disturbance as an outcome measure using 3 different measures. There was a positive treatment effect reported in 1 study (20) and in the other 3, there was no significant difference between the groups.

\section{Side effects and adverse events}

In 6 studies, there were either no adverse events or side effects reported or no differences between the intervention and control groups reported.

In 2 studies, there was a greater decline in MMSE in the intervention group $(4,18)$. In one study, this effect was seen in the intervention group as a whole (vitamin $\mathrm{E}+$ vitamin C + alpha lipoic acid), and in the other the greater deterioration was seen in the people who did not have a plasma response to vitamin E (the "non-respondents").

In the curcumin study (21), participants taking curcumin had a statistically significant lower plasma haemotocrit and higher glucose. It is unlikely that these effects are clinically significant. This study also stated "complaints attributable to the endocrine system" were less common in the $2 \mathrm{gm}$ curcumin group compared to placebo or the $4 \mathrm{gm}$ group. ( $3 \%$ vs $17 \%$ vs $19 \% \mathrm{p}=0.02$ ). The exact endocrine complaints are not stated. There was no significant difference in the withdrawal rate due to adverse events between the groups.

In total 1 patient (33\%) in the zinc study (19) developed low plasma levels of caeruloplasmin, thought to be directly attributed to taking zinc.

In people taking vitamin E in the Sano study (18), more people had the following events compared to the placebo group: dental events ( $n=1$ vs $n=0 . P=0.023)$, falls $(n=12$ [14\%] vs $n=4[5 \%] \mathrm{p}=0.005)$ and syncope ( $\mathrm{n}=4$ vs $\mathrm{n}=7$ $\mathrm{p}=0.031$ ).

\section{Figure 1}

Flow diagram for literature search

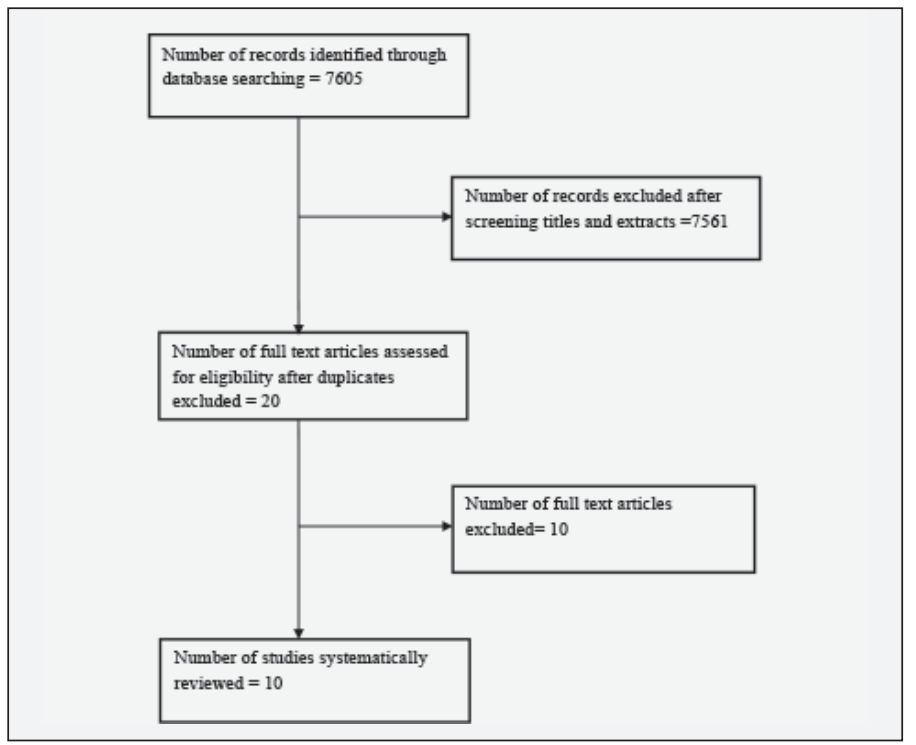


Table 3

Risk of bias table

\begin{tabular}{|c|c|c|c|c|c|c|c|c|}
\hline Study & $\begin{array}{l}\text { Sequence } \\
\text { generation } \\
\text { (selection bias) }\end{array}$ & $\begin{array}{l}\text { Allocation } \\
\text { concealment } \\
\text { (selection } \\
\text { bias) }\end{array}$ & $\begin{array}{l}\text { Blinding } \\
\text { of } \\
\text { participants } \\
\& \\
\text { investigators } \\
\text { (perfor- } \\
\text { mance bias) }\end{array}$ & $\begin{array}{l}\text { Blinding } \\
\text { of outcome } \\
\text { assessment } \\
\text { (detection bias) }\end{array}$ & $\begin{array}{l}\text { Incomplete } \\
\text { outcome } \\
\text { reporting } \\
\text { (attrition bias) }\end{array}$ & $\begin{array}{l}\text { Intention to } \\
\text { treat analysis }\end{array}$ & $\begin{array}{l}\text { Selective } \\
\text { outcome } \\
\text { reporting } \\
\text { (reporting bias) }\end{array}$ & Other bias \\
\hline Asayama (20) & Unknown & Unknown & Unknown & Unknown & Low & Yes & Low & \\
\hline Brewer (19) & Unknown & Unknown & Unknown & Unknown & Unknown & Unknown & unknown & $\begin{array}{l}\text { No baseline } \\
\text { characteristics } \\
\text { provided. Post } \\
\text { hoc analysis }\end{array}$ \\
\hline Dysken (22) & Low & Low & Low & Low & Low & Yes & No & $\begin{array}{l}\text { Vast majority men } \\
\text { but unlikely to be } \\
\text { a significant bias }\end{array}$ \\
\hline Galasko (4) & Unknown & Unknown & Low & Low & Low & Yes & No & \\
\hline Krikorian (17) & Unknown & Unknown & Low & Low & Low & Yes & Low & \\
\hline Lloret (16) & Low & Unknown & Unknown & Unknown & High & Unknown & Unknown & Post hoc analysis \\
\hline Alavi Naeini (23) & Low & Unknown & Unknown & Unknown & High & No & Low & $\begin{array}{l}\text { MMSE signifi- } \\
\text { cantly improved } \\
\text { in both groups. } \\
\text { Could be due to } \\
\text { familiarity and } \\
\text { so is a potential } \\
\text { confounder }\end{array}$ \\
\hline Petersen (24) & Low & Unknown & Unknown & Unknown & Low & Yes & Low & \\
\hline Ringman (21) & Unknown & Unknown & Unknown & Unknown & Low & Yes & Low & \\
\hline Sano (18) & Low & Unknown & Unknown & Unknown & Low & Yes & Low & $\begin{array}{l}\text { Significant } \\
\text { baseline difference } \\
\text { in MMSE }\end{array}$ \\
\hline
\end{tabular}

\section{Summary of findings}

The findings of this systematic review do not support the use of antioxidant supplements to slow cognitive, functional or behavioural deterioration in people with $\mathrm{AD}$ or MCI. There were no consistent adverse effects found overall however two studies raised concern of possible worsening of cognition in certain circumstances $(4,16)$.

Regarding cognition, 4 out of the 7 studies involving people with $\mathrm{AD}$ found a small positive treatment effect $(16,18-20)$. 2 of these studies $(16,19)$ however should perhaps be regarded as exploratory studies since the positive treatment effects were found in a post hoc analysis. Furthermore the risk of attrition bias was judged to be high in 1 of these studies (16) therefore the results may not be reliable. In neither of the remaining 2 studies $(18,20)$, was the treatment effect supported by the other measures of cognition used: Sano (18) reported a change in the BDS of 4.0 in the vitamin E group compared to 5.4 in the placebo group (in addition to the 230 day increased time to either institutionalisation; loss of ability to perform at least two of three basic activities of daily living, severe dementia, defined as CDR rating of 3.) There was no significant difference with MMSE. The risk of bias was overall low in the Sano study. Asayama (20) reported a mean change of -4.3 (3.6) in the ADAS-cog in the intervention group compared to 0.3 (1.3) in the control group. There was no significant difference with MMSE however and the risk of bias with the study was largely unclear.

One study (4) reported a deterioration of MMSE score in people taking vitamin E/ Vitamin C/ alpha lipoic acid. The overall risk of bias was low in this study. A different study (16) reported a greater deterioration in people who did not have a plasma response to vitamin E (the "nonrespondents").

Of the 3 studies where participants had MCI, only 1 (17)reported a positive treatment effect and again, this was only in one of the 4 measures of cognition used in the trial. Since the number of participants was only 12 in this study, it should also probably be regarded as an exploratory trial.

Of the 4 studies in AD participants which included a measure of functional ability as an outcome measure, 2 reported a positive treatment effect $(18,22)$ and 2 reported that there was no effect $(4,21)$. The Dysken study (22) was judged to be the highest quality trial included in this review and reported an improvement in one of 2 measures of function used in the study. Overall, $2000 \mathrm{IU}$ of vitamin $\mathrm{E}$ daily plus and AChEI reduced progression of functional decline by $19 \%$ per year compared with 
placebo plus AChEI as measured by the ADCS-ADL inventory however secondary measures of caregiver time and dependence were not reduced on the CAS. It is noteworthy however that despite there being a slower functional decline in the vitamin E group, there was not any significant delay in cognitive decline which is a more specific feature of AD. One author has however proposed that this could be because "functional ability may be a more sensitive measure of AD progression" (25). In addition, paradoxically a combination of memantine and alpha tocopherol had a lesser effect than either treatment alone. The authors postulate that memantine may interfere with the antioxidant properties of vitamin E. Sano (18) reported a significant improvement in the dependence scale score of 76 vs 86 in the vitamin E group compared to placebo.

Only $1 \mathrm{MCI}$ study measured function and there was no statistically significant treatment effect (24).

Of the 4 studies where participants had AD and an assessment of mood or behaviour was carried out (4, 20-22) only 1 study reported a significant treatment effect where the ADAS non cog improved by -4.1 (2.2) points in the melatonin group and by -0.8 points in the placebo group (20). The risk of bias was largely unknown in this study.

None of the studies evaluating MCI measured behaviour or mood.

In terms of safety, there do not seem to be any side effects which are common across the included studies.

For most domains of bias not enough information was provided by the authors to make a definitive judgement therefore the risk of bias is largely unknown. (See risk of bias table). There was only 1 study which had a low overall risk of bias and in this study, there was some evidence that antioxidant supplements may have a positive effect of functional decline in $\mathrm{AD}(22)$.

\section{Discussion}

\section{Strengths and limitations}

This is the first systematic review to evaluate trials of the main antioxidant supplements in people with AD and MCI. It was performed and reported according to PRISMA guidance and included a comprehensive literature search and evaluation of the literature.

Limitations of this review are that it was conducted by only one reviewer, the number of included studies was relatively small and the search strategy excluded 508 non-English language publications from the screening process. Furthermore, it is possible that the supplements reviewed have other mechanisms of action that may affect outcomes rather than simply acting as antioxidants. Curcumin for example, has been shown to bind to amyloid plaques and inhibit fibril formation (26). A further issue with curcumin is that it has low bioavailabilty in plasma as well as low water solubility and a short half -life.

The internal validity of this review, i.e. the extent to which observed treatment effects can be attributed to the antioxidant rather than confounding, cannot be confidently assessed because with the exception of one study (22), the information provided by the study authors was not sufficiently explicit to make an accurate assessment. Only the Dysken study (22) was judged to have good internal validity owing to the transparency and detail provided by the authors.

A further limitation with most of the studies included in this review is that they are likely to be underpowered: in total 6 studies had less than 100 participants. Only the Dysken study, which had 613 participants in total, included a power calculation.

All studies used similar methods of diagnosing MCI or AD which supports good external validity (Ie this is in support of being able to correctly generalise the results to the population of people with $\mathrm{AD}$ or $\mathrm{MCI}$ outside of the study). The duration of the study is of particular concern however in 3 of the trials $(4,17,20)$ which lasted for 16 weeks, 12 weeks and 4 weeks respectively. This may not be adequate follow up with respect to harm or benefit and thus is a risk to external validity.

\section{Clinical practice and research implications}

There is not presently adequate evidence to support the use of antioxidants to slow cognitive, functional or behavioural decline in $\mathrm{AD}$ or MCI.

Overall, the safety data from this systematic review was not concerning however caution is warranted owing to the fact that the duration of follow up was short in many of the included studies and also in view of the finding reported by a large Cochrane review that beta carotene, vitamin $\mathrm{E}$ and possibly higher doses of vitamin A seem to increase mortality (7).

Future research should perhaps be aimed at advancing knowledge of the role of oxidative stress and antioxidants in the pathogenesis of Alzheimer's dementia and mild cognitive impairment because it is possible that the relationship is more complex than is currently thought and furthermore there is a suggestion antioxidants are harmful in some circumstances $(27,28)$.

If further trials are then carried out, it is important that trials are adequately powered and of a sufficient duration to be able to detect effects. They should also take into account that patients with cognitive impairment are less likely to concord with treatment (29). As suggested by the authors of a recent review evaluating the limitations of RCTs for non-pharmacological interventions for MCI (30), greater standardisation of methods (including outcome measures) would allow better comparison and generalisation of study outcomes. Finally, authors should consider reporting future studies according to CONSORT guidelines (31) so that readers can accurately assess validity. 


\section{Conclusions}

This systematic review does not suggest overall that antioxidant supplements have a beneficial effect on cognitive, functional or behavioural decline in Alzheimer's dementia or mild cognitive impairment.

The evidence for the role of oxidative stress in the pathogenesis of Alzheimer's disease provides a clear rationale for the use of antioxidant therapies in AD yet the results of clinical trials have overall been disappointing. Possible reasons for this discrepancy include that the existing research generally has methodological limitation and that the relationship between antioxidants and the development of AD is more complicated than is currently realised.

The overall risk of harm associated with short term antioxidant supplementation appears to be low based upon this review however caution is warranted owing to findings from other large systematic reviews (7).

Conflict of interest: No conflict of interest.

\section{References}

1. Rosini M, et al. Oxidative stress in Alzheimer's disease: are we connecting the dots? J Med Chem 2014;57(7): p. 2821-31.

2. Mecocci P, MacGarvey U, Beal MF. Oxidative damage to mitochondrial DNA is increased in Alzheimer's disease. Ann Neurol 1994;36(5): p. 747-51.

3. Wang J, Markesbery WR, and Lovell MA. Increased oxidative damage in nuclear and mitochondrial DNA in mild cognitive impairment. J Neurochem 2006;96(3): p. 825-32.

4. Galasko DR, et al. Antioxidants for Alzheimer disease: a randomized clinical trial with cerebrospinal fluid biomarker measures. Arch Neurol 2012;69(7): p 836-41.

5. Farina N, et al. Vitamin E for Alzheimer's dementia and mild cognitive impairment. Cochrane Database Syst Rev 2012;11: p. Cd002854.

6. Lonn E, et al. Effects of long-term vitamin E supplementation on cardiovascular events and cancer: a randomized controlled trial. Jama 2005;293(11): p. 1338-47.

7. Bjelakovic G, et al. Antioxidant supplements for prevention of mortality in healthy participants and patients with various diseases. Cochrane Database Syst Rev 2012;3: p. Cd007176

8. Schurks M, et al. Effects of vitamin E on stroke subtypes: meta-analysis of randomised controlled trials. BMJ , 2010;341: p. c5702

9. Klein EA, et al. Vitamin E and the risk of prostate cancer: the Selenium and Vitamin E Cancer Prevention Trial (SELECT). Jama 2011;306(14): p. 1549-56.

10. Hercberg S, et al. The SU.VI.MAX Study: a randomized, placebo-controlled trial of the health effects of antioxidant vitamins and minerals. Arch Intern Med 2004;164(21): p. 2335-42.
11. Omenn GS, et al. Effects of a combination of beta carotene and vitamin A on lung cancer and cardiovascular disease. N Engl J Med 1996;334(18): p. 1150-5.

12. Liberati A et al. The PRISMA statement for reporting systematic reviews and meta-analyses of studies that evaluate healthcare interventions: explanation and elaboration. BMJ 2009;339: p. b2700.

13. World Health Organisation and the Food and Agricultural Organisation of the United Nations. Vitamin and mineral requirements in human nutrition: Geneva, 2004.

14. Birks J, Grimley Evans J. Ginkgo biloba for cognitive impairment and dementia. Cochrane Database Syst Rev 2009;(1): p. Cd003120.

15. The Cochrane Collaboration. Cochrane Handbook for Systematic Reviews of Interventions: London, 2011

16. Lloret A, et al. Vitamin E paradox in Alzheimer's disease: it does not prevent loss of cognition and may even be detrimental. J Alzheimers Dis 20009;17(1): p. 143-9.

17. Krikorian $\mathrm{R}$, et al. Concord grape juice supplementation improves memory function in older adults with mild cognitive impairment. Br J Nutr 2010;103(5): p. 730-4.

18. Sano M, et al. A controlled trial of selegiline, alpha-tocopherol, or both as treatment for Alzheimer's disease. The Alzheimer's Disease Cooperative Study. N Engl J Med 1997;336(17): p. 1216-22.

19. Brewer GJ, Kaur S. Zinc deficiency and zinc therapy efficacy with reduction of serum free copper in Alzheimer's disease. Int J Alzheimers Dis, 2013: p. 586365.

20. Asayama K, et al. Double blind study of melatonin effects on the sleep-wake rhythm, cognitive and non-cognitive functions in Alzheimer type dementia. J Nippon Med Sch 2003;70(4): p. 334-41.

21. Ringman JM, et al. Oral curcumin for Alzheimer's disease: tolerability and efficacy in a 24-week randomized, double blind, placebo-controlled study. Alzheimers Res Ther 2012;4(5): p. 43.

22. Dysken MW, et al. Effect of vitamin E and memantine on functional decline in Alzheimer disease: the TEAM-AD VA cooperative randomized trial. Jama 2014;311(1): p. 33-44.

23. Alavi Naeini AM, et al. The effect of antioxidant vitamins $E$ and $C$ on cognitive performance of the elderly with mild cognitive impairment in Isfahan, Iran: a double-blind, randomized, placebo-controlled trial. Eur J Nutr 2014;53(5): p. 1255-62

24. Petersen RC, et al. Vitamin E and donepezil for the treatment of mild cognitive impairment. N Engl J Med 2005;352(23): p. 2379-88

25. Evans DA, Morris MC, Rajan KB. Vitamin E, memantine, and Alzheimer disease. Jama, 2014;311(1): p. 29-30.

26. Yang $\mathrm{F}$ et al. Curcumin inhibits formation of amyloid beta oligomers and fibrils, binds plaques, and reduces amyloid in vivo. J Biol Chem. 2005 Feb 2005;18;280(7):5892-901

27. Underwood BR, et al. Antioxidants can inhibit basal autophagy and enhance neurodegeneration in models of polyglutamine disease. Hum Mol Genet 2010;19(17): p. 3413-29.

28. Harrison FE. A critical review of vitamin C for the prevention of age-related cognitive decline and Alzheimer's disease. J Alzheimers Dis 2012;29(4): p. 711-26.

29. Hayes TL, et al. Medication adherence in healthy elders: small cognitive changes make a big difference. J Aging Health 2009;21(4): p. 567-80.

30. Horr T, Messinger-Rapport B and Pillai JA. Systematic review of strengths and limitations of randomised controlled trials for non-pharmacological interventions in mild cognitive impairment: Focus on Alzheimer's Disease. J Nutr Health Ageing 2015;19 (2) 141-15

31. Schulz KF, Altman DG, and Moher D. CONSORT 2010 Statement: updated guidelines for reporting parallel group randomised trials. BMC Med 2010;8: p. 18. 